\section{Practice Research}

\section{Do general practitioners have different "referral thresholds"?}

RICHARD O CUMMINS, BRIAN JARMAN, PATRICIA M WHITE

One of the most interesting puzzles in general practice is why
doctors differ so greasly in the frequency with which they refer

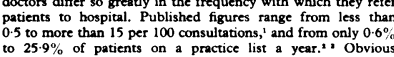
to $25.9 \%$ of patients on a prectice list a year. "2 Obvious
differences in patient characteristics, such as age, sex, sociel diferences in patient characteristics, such as age, sex, social
class, type and severity of problem, and distance from the
practice; in doctor characteristics, such as age, years in general practice and in a particular practice, special medical interests
and postgraduate training; and in practice characteristics, such as size of list, work load, urban or rural setting, partnership or
single-handed structure, and distance from hospital ${ }^{-11}$ may single-handed structure, and distance from hospital ${ }^{-11}$ may
explain many of these marked variations.
These differences in referral rates may also be explained by

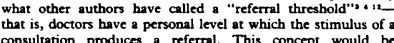
consultation produces ar referral. This concept would be
supported if doctors were observed to refer at dissimilar rates
even when patient, doctor, and prectice characteristics were even when patient, doctor, and practice characteristics wer
the same. Unfortunately, only a few studuess', of the referral
proceses have controlled for more than one of these characteristic at a time. 1971 , the general practice partnership of one of us (B) hask kepp extensive recerald on on every ponensultation. The us ize and
detail of these data allowed us to carry the observations

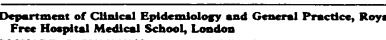

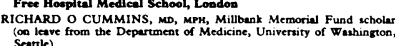
Lumos Grove Heesth Centre, Londoen Nws aEC

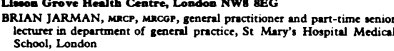

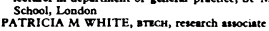

previous workers one step further-we compared the referral
rates of several doctors while a number of patient and practice variables were concrolled. Our purpose was to examine the hypothesis that general practitioners have a personal referral
threshold. Practice characteristics were the same for each were then made for differences in patient characereristics and the
doctors scill had different referral rates, then the existence of a Methods

The practice is loosared in the inner London Area Health Authority
of Kensingsion, Chelsed and wessminster. Medical problems in this

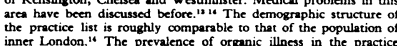

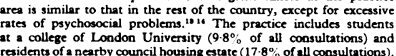

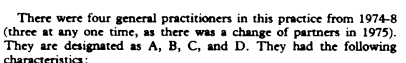

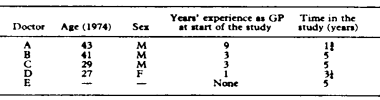

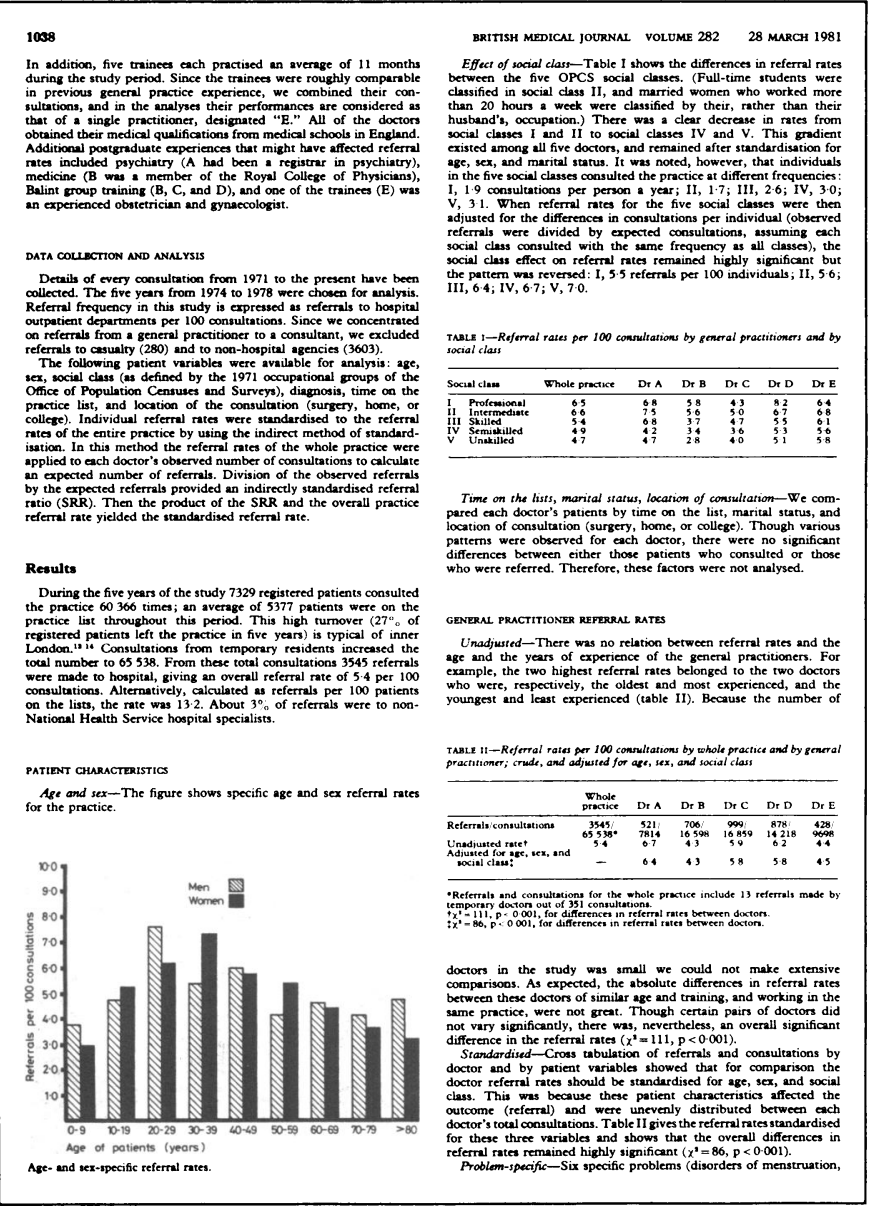

1040

Pitfalls in Practice

\title{
Employment law
}

IV: Can I still dismiss?

NORMAN ELLIS

Mann employers, parricularly those with no more than a handful
of staff, are fearful about the prospects of dismissing staff. away from them by current employment legisatiotion. This is
not true. An employer still has the right to dismiss an employ not true. An employer still has the right to dismiss an employece,
but if the procedure adopted and the reasons for the dismissal but if the procedure adopted and the reasons for the dismissal
are not demonstrably fair then substantial compensation may
be awarded to the employec.

In fact it is ussually the employer who has neglected his
managemenent responsibilities who is at risk of being involved the difficulties that doctor approach to their selection, recriviment, craining, and super-
vision. In a previous article Dr John Oldroyd provided a cas vision. In a previous article Dr John Oldroyd provided a case
study sbowing the many piffalls that force the docror who
iignores his responsibilities as a manager. A brief reminder of ignores his responsibilities as a manager. A brief reminder of
these responsibilities may be helpful. Firsty, at the outset,
when a new member of staff is recruited, it is essential to have an a curate iob description and to adopt a proper procedure
for the interview and selection. Secondly, when an offer of a for the interview and selection. Secondly, when an offer of
job is made both the doctor and the employee should be aware
of the importance of the probationary period. Its lenght may

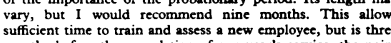
sufficient time to train and assess a new employec, but is threc
months before the completion of one years sservice, the point
after which many individual employment rights begin to apply. The probationary period is crucial. But befoes we strir thinking of what action may be required to improve performance
in the job, a new member of the steff should be told wh is required and given every encouragenent and assistance to do
the job satisfactorily. Mann employers socm to forget the
obvious and essential need to explain to new staff what is
required of them. If this is done and performance then falls the employee of this and to encourage him or her to improve. At cach stage a written record must be kept for future reference,
and if the point is reached when it seems that satisfartory
performance cannot be achieved, then the employee should be

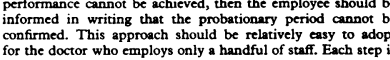

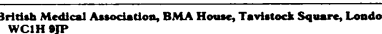

WCLMA OPP
Ofifcr

TITSH MEDICAL JOURNAL VOLUME $282 \quad 28$ MARCH 1981

logical and casy to follow. And it should minimise the risk of
having to dismiss staff. In shorr, each mployer should have a recogenised procedure for handling disciplinary manters and
grievances, and what has been described here is in fact the outline of such a procedure.
If even after following this procedure, having taken all the

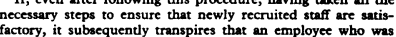
previously satisfactory is no longer so, or that a serious offence
is commintred that requires disciplinary action, the doctor has the right ultimately to dismiss. But care must be taken to follow
closely to the disciplinary procedure as stated in the contract of taken.

Uneatisfactory steaff

No doubt a few general practitioners employ staff whose
performance is well below the standard required. This is probbably a legacy of previous neglect of their responsibilities as employers- a casual approacch to recruitment, inadequate
training and supervision, and the probationary period has been
omitred from the contract. The point has been reached where something should be done, but none of the parteners has either
the courage or inclination to do anything. Offen the BMA member will turn to the BMA Regional Office for advice.
Although the position of staff who are unsatisfactory but
have had long service wivh the practice is always dificult to
resolve, it is not irretrievable. It must be remembered that the

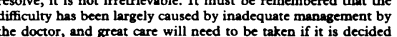
proceed with disciplinary action, which may end in dismissal. The employee who has been working unsatisfactorily, often for
many years, has strong grounds for arguing that his or ber
performonce could be presurumed to be satififactory simply performance could be pressumed to be satisfactory simply
because no one had expressed any view to the contrary. The because no one had expressed any view to the contrary. The
industrial tribunals almost invariably interpret the lack of any criticism from the employer as a reasonable basis for an em-
ployec presuming that his work was satisfactory. Thus the doctor's laudable efforts to retrieve a situation that has been
allowed to driff for years end to act in acoordance with his difficulties and require the advice and assistance of those who

号

Employees have the right not to be unfairly dismissed. Any
employee who thinks he has been unfairly dismmised may seck 